\title{
Composição centesimal em músculo de peixes no litoral do estado da Bahia/ Brasil
}

\author{
Centesimal composition in fish muscle on the coast of Bahia / Brazil \\ Zenira Cardoso Vilasboas Viana'; Edevaldo da Silva², Gilenio Borges Fernandes; \\ Vera Lúcia Cancio Souza Santos ${ }^{4}$
}

\begin{abstract}
${ }^{1}$ Professora Associada do Departamento de Biofunção do Instituto de Ciências da Saúde da UFBA, Mestrado em Ciência e Tecnologia de Alimentos pela Escola Superior de Agricultura Luiz de Queiroz - USP, Doutorado em Química pela UFBA

${ }^{2}$ Professor Adjunto, Unidade Acadêmica de Ciências Biológicas - UFCG, Mestrado e Doutorado em Química Analítica- UFBA.

${ }^{3}$ Professor Associado do Instituto de Matemática da UFBA, Mestrado em Agronomia pela Escola Superior de Agricultura Luiz de Queiroz-USP, PhD Meteorologia Agrícola e Estatística pela lowa State University - USA. ${ }^{4}$ Professora Associada do Departamento de Química Analítica, Instituto de Química da UFBA, Mestrado em Química Analítica pela UFBA e PhD em Biogeoquímica, Universidade de Liverpool, Inglaterra.
\end{abstract}

\begin{abstract}
Resumo
Introdução: O peixe, devido à alta qualidade em proteína e grande quantidade de nutrientes, é importante na dieta dos humanos. $O$ alto teor de ácidos graxos poliinsaturados da série $\omega$ (ômega) 3 e $\omega-6$ presente nos peixes previne a formação do colesterol do tipo LDL (lipoproteína de baixa densidade). Objetivo: Este trabalho avaliou a composição centesimal de tecido muscular de espécies de peixes Lutjanus synagris (ariacó) e Ocyurus chrysurus (guaiuba), que foram amostradas mensalmente, no período de março de 2004 a fevereiro de 2005, na área costeira de Porto Seguro (PS) e duas espécies Opisthonema oglinum (sardinha-laje) e Mugil spp (tainha) na região costeira da baía de Todos os Santos (BTS). No músculo de cada espécie, as análises do teor de umidade, cinzas, proteínas e lipídios totais foram realizadas. Metodologia: Análises químicas realizadas foram teor de umidade, teor de cinzas, teor proteico pelo método de Kjeldahl e o teor de lipídios totais determinado por método de extração a frio. A análise de variância (ANOVA), através do teste $\mathrm{F}$ de Snedecor $(\mathrm{p}<0,05)$, foi utilizada para identificar diferenças significativas. Resultados: Os resultados da análise centesimal dos peixes foram: umidade de $73,0 \%$ a $79,9 \%$, cinzas $1,0 \%$ a 2,0\%, proteínas $17,0 \%$ a $23,2 \%$ e lipídeos totais de 0,4 \% e 2,9\%. Houve variação significativa do teor dos parâmetros umidade, proteínas e lipídios totais estudados ao longo dos doze meses tanto para as espécies ariacó e guaiuba coletadas na região costeira de Porto Seguro como para as espécies sardinha-laje e tainha coletadas na região costeira da Baía de Todos os Santos. Conclusão: Ariacó está associada ao maior teor de lipídios totais. A sardinha-laje apresentou teor mais elevado em cinzas indicando maior conteúdo em minerais. A guaiuba apresentou maior teor de umidade. A tainha, espécie amostrada na BTS, apresentou os maiores percentuais de proteínas.
\end{abstract}

Palavras-chave: Peixes. Análise Química. Costa.

\begin{abstract}
Background: Fish is one of the most important foods in the diet of humans due to high quality protein and large amounts of nutrients. The high content of polyunsaturated fatty acids of the series $\omega$ (omega) 3 and $\omega-6$ in fish prevents the formation of type LDL cholesterol (low-density lipoprotein). Objective: This paper presents a study of the chemical composition of muscle tissue of four fish species; Lutjanus synagris (ariacó), Ocyurus chrysurus (Guaiuba) Opisthonema oglinum (sardine-slab) and Mugil spp (mullet); The first two species sampled in the coastal area of Porto Seguro and the latest in the coastal region of the Todos os Santos bay (BTS). The analysis of moisture content, ash, protein and total lipids were carried out in muscle of each fish species collected monthly from March 2004 to February 2005. Methodology: The moisture content, ash content, protein content by the Kjeldahl method and total lipid content, determined by the method of cold extraction were determined. The analysis of variance (ANOVA) through Snedecor F-test $(p<0.05)$ was used to identify significant differences. Results: The results of proximate analysis of fish collected in two regions of the coast of Bahia were: moisture $73.7 \%$ to $79.9 \%$, ash $1.02 \%$ to $2.40 \%$, protein $17.0 \%$ at $23.2 \%$ and total lipids $0.4 \%$ to $2.9 \%$. There was a variation in the content all the parameters (moisture, proteins and total lipids) studied over the twelve months for both species collected in the coastal region of Porto Seguro (ariacó and guaiuba) as for the species collected in the coastal region of the Todos os Santos bay (sardinha-laje and tainha). Conclusions: Ariacó is associated with higher total fat content. The higher moisture content was observed in quaiúba, species from Porto Seguro while the lower moisture content in tainha, species from Todos os Santos bay (BTS). The higher ash content was observed in sardinha-laje. The highest percentages of protein were observed in tainha and content of total lipids in ariacó, species of Porto Seguro (PS).
\end{abstract}

Keywords: Fishs. Chemical Analysis. Coasts.

Correspondência / Correspondence: Zenira Cardoso Vilasboas Viana

Av. Reitor Miguel Calmon s/ $\mathrm{n}$ - Vale do Canela, CEP 40.110-100

Salvador, Bahia, Brasil. Tel.: (71) 3283-8885. (71) 9983-9369

E-mail: zenira@ufba.br 


\section{INTRODUÇÃO}

O peixe é um dos alimentos mais importantes na dieta dos humanos devido à alta qualidade em proteína e grande quantidade de nutrientes, além de excelente digestibilidade. Muitas das espécies de peixes têm algum valor de mercado direto ou fazem parte de cadeias alimentares que suportam outros recursos economicamente importantes ${ }^{1}$. Os lipídios provenientes de organismos marinhos possuem baixa quantidade de óleos saturados (11 a 17\%), enquanto que, em média, na carne de suínos o percentual é de $36 \%$ e em bovinos de $48 \%{ }^{2}$. O alto teor de ácidos graxos poliinsaturados da série $\omega$ (ômega) 3 e $\omega-6$ presente nos peixes previne a formação do colesterol do tipo LDL (lipoproteína de baixa densidade) ${ }^{3}$.

Na região Nordeste, no ano de 2005 , a produção de pescado foi da ordem de aproximadamente 153 mil toneladas, sendo $72,6 \%$ referentes aos peixes. No Estado da Bahia, neste mesmo ano, a produção de peixes representou $70,0 \%$ do total de pescados, sendo $10,2 \%$ referentes às sardinhas e $4,1 \%$ às tainhas 4 .

Este trabalho apresenta uma avaliação da composição centesimal (umidade, proteínas, cinzas e lipídios totais) de tecido muscular de espécies de peixes coletadas em duas regiões do litoral do Estado da Bahia, com a finalidade de contribuir com informações referentes à parte nutricional dos peixes comercializados e consumidos pela comunidade dessas regiões.

\section{MATERIAIS E MÉTODOS}

O Estado da Bahia possui uma extensa zona costeira e a cidade de Salvador foi o município litorâneo que em 2006 apresentou a maior produção de pescado (11,3\%). A espécie sardinha-laje (Opisthonema oglinum) registrou a maior produção neste mesmo ano, representando $14,8 \%$ do total ${ }^{5}$. As áreas amostradas no litoral do Estado da Bahia (Baía de Todos os Santos, no Recôncavo e Porto Seguro, no Extremo Sul) se destacam em produção em pescados.

A Baía de Todos os Santos (BTS) é uma das maiores baías da costa brasileira, com aproximadamente $1100 \mathrm{Km}^{2}$. Nos anos de 2005 e de 2006 a produção (em toneladas) de pescados desembarcada no município de Salvador foi de $2.982,7$ e 4.870,5 respectivamente5. A produção (em toneladas) desembarcada em Porto Seguro no período de 2005 e 2006 foi 1.206,7 e 1.516,8 respectivamente ${ }^{5}$.

As espécies de peixes investigadas neste estudo foram selecionadas em função da relevância na produção de pescados do Estado da Bahia, além do fator sócio-econômico e importância para o consumo. A coleta das espécies de peixes sardinha-laje, tainha (Mugil spp.), guaiúba (Ocyurus chrysurus) e ariacó (Lutjanus synagris) foram realizadas mensalmente, no período de março de 2004 a fevereiro de 2005. O músculo de cada espécie de peixe foi separado e acondicionado em saco de polietileno e então congelado até o procedimento das análises ${ }^{6}$.
Houve um esforço no sentido de garantir o trabaIho com peixes do mesmo tamanho, mas eventualmente ocorreram variabilidades. Todo o material utilizado foi previamente descontaminado em banhos de Extran neutro a $0,5 \%$ por $24 \mathrm{~h}$. Em seguida foi submetido a duas lavagens com água destilada e por último com água ultra pura Mil li-Q ${ }^{\circledast}$ (resistividade de $18.2{\mathrm{M} \Omega \mathrm{cm}^{-}}^{-}$) e armazenado em ambiente isento de poeira até análise ${ }^{6}$.

\section{Análises químicas}

\section{Umidade}

Cada amostra $( \pm 40 \mathrm{~g})$ foi acondicionada em placa de Petri, previamente pesada. Em seguida, colocada na estufa entre 105 C e 120 C, esfriada em dessecador e então pesada. Este procedimento foi repetido até obtenção de peso constante ${ }^{6}$.

\section{Cinzas}

Cada amostra seca $( \pm 1 \mathrm{~g})$ previamente carbonizada foi acondicionada em cadinho de porcelana, incinerada em mufla à temperatura de aproximadamente 600 으, até peso constante?.

\section{Proteínas}

O conteúdo total de nitrogênio foi determinado pelo método de Kjeldahl e o teor de proteínas calculado pela multiplicação do valor de nitrogênio pelo fator geral $6,25^{7}$.

\section{Lipídios}

O conteúdo de lipídios totais foi determinado por método de extração a frio ${ }^{8}$.

Os resultados de todas as análises químicas foram expressos em percentagem, $\mathrm{g} \%^{6}$.

\section{Análise estatística}

A análise de variância (ANOVA), através do teste $F$ de Snedecor $(p<0,05)$, foi utilizada para identificar diferenças significativas ao nível de $5 \%$ na composição centesimal dos peixes, durante o período de 12 meses. Sempre que o teste $F$ da ANOVA apresentou significância foi aplicado o procedimento $t$ múltiplo disponível no $R^{9}$, versão 2.13 , com os $p$-valores ajustados por single-step, para comparações de múltiplas de média ${ }^{10,11}$.

\section{RESULTADOS E DISCUSSÃO}

A tainha, espécie amostrada na BTS, apresentou o menor teor de umidade, enquanto a guaiúba, espécie amostrada em Porto Seguro, apresentou o maior valor (Tabela 1).

Embora, até o presente momento, poucas informações sobre ariacó e guaiúba tenham sido encontradas na literatura, a composição centesimal em tecido muscular de diferentes espécies de peixes pesquisadas por outros autores encontraram a variação do teor de umidade na faixa de 64 a $90 \%^{12-15}$, consistentes aos obtidos no presente estudo. A tainha (Mugil spp; 73\%) apre- 
sentou teor de umidade mais elevado que a Sardinella brasiliense (sardinha verdadeira; $72 \%$ ) e mais baixo que o teor observado na tainha (Mugil cephallus; $78,4 \%)^{16}$. 0 teor de umidade do pescado e de seus derivados é de fundamental importância para se determinar a condição de tempo de prateleira e definir metodologias adequadas para a conservação destes produtos.

Houve variação do teor dos parâmetros umidade, proteínas e lipídios (Tabelas 1, 2 e 3) estudados ao longo dos doze meses tanto para as espécies ariacó e guaiuba coletadas na região costeira de Porto Seguro (PS) como para as espécies sardinha-laje e tainha coletadas na região costeira da Baía de Todos os Santos (BTS).

$\mathrm{Na}$ avaliação do teor de umidade, a interação entre espécie e mês foi estatisticamente significante ( $p$ -valor=0,0422). O estudo detalhado desta interação foi feito comparando os meses dentro de cada espécie e as espécies dentro de cada mês. Na comparação das médias da umidade nos meses dentro de cada espécie, diferenças de médias de magnitude $3,11 \%$ ou maiores são significativas estatisticamente (inferência simultânea) ao nível de 5\%. Do mesmo modo, na comparação das médias da umidade nas espécies dentro de cada mês, diferenças de médias de umidade, entre espécies, de 2,43\% ou maiores são significativas estatisticamente (inferência simultânea) ao nível de 5\%. Ambos os valores obtidos podem ser observados na Tabela 1.

Observou-se uma tendência geral linear de decrescimento não muito acentuado da umidade no perío- do, mas, não significativa, em decorrência da grande variabilidade. Nos meses de julho, agosto e setembro de 2004, o comportamento das espécies são muito similares e bastante discrepantes nos meses de março e novembro de 2004 e fevereiro de 2005 podendo ser observadas na Figura 1.

Os resultados do teor de cinzas encontrados no presente trabalho foram similares aos encontrados, em outras espécies, na literatura ${ }^{14,16,17}$. No entanto, o teor de cinzas da sardinha-laje, espécie da BTS, foi o maior dentre todas as espécies avaliadas, seguida pela tainha (Figura 1). Esses valores foram consistentes com aqueles encontrados na literatura para as mesmas espécies ${ }^{12}$. 0 teor de cinzas, indica o teor total dos nutrientes como cálcio, potássio, sódio, magnésio, ferro, cobre, cobalto, alumínio, sulfato, cloreto, silicato, fosfato e outros. Isto pode indicar que sardinha-laje e a tainha são espécies que possuem maior concentração de importantes nutrientes, principalmente cálcio e fósforo ${ }^{18,19}$. Em geral, o teor de cinzas nos peixes varia entre 1 a $2 \%$ do total da composição centesimal e é influenciado pelo tipo de alimentação das espécies ${ }^{17}$. Para esse parâmetro, apenas o efeito de espécie foi significativo ao nível de 5\%. Aplicou-se a ANOVA e comparações múltiplas apenas em espécie, com o ajuste dos $p$-valores por single-step ${ }^{11}$. Diferenças estatisticamente significativas ( $p$-valor $<0,05$ ) não foram reveladas para as espécies ariacó (PS) e tainha (BTS) e entre ariacó (PS) e guaiuba (PS). O teor de cinzas avaliado no período detectou que, estatisticamente, a

Tabela 1.Teor médio de umidade (\%) nas espécies no período analisado de março (1) de 2004 a fevereiro (12) de 2005

\begin{tabular}{|c|c|c|c|c|c|c|c|}
\hline mês & ariacó & mês & guaiuba & mês & sardinha & mês & tainha \\
\hline 1 & $79,1^{\mathrm{Aa}}$ & 1 & $79,4^{\mathrm{Aa}}$ & 1 & $75,4^{\mathrm{aBbc}}$ & 1 & $75,8^{\text {Bbcd }}$ \\
\hline 2 & $78,6^{\mathrm{Aa}}$ & 2 & $79,0^{\text {Aab }}$ & 2 & $77,2^{\text {Aab }}$ & 2 & $78,1^{\mathrm{Aab}}$ \\
\hline 3 & $77,5^{\text {Aab }}$ & 3 & $77,2^{\text {Aabc }}$ & 3 & $76,1^{\mathrm{Aabc}}$ & 3 & $76,1^{\text {Aabcd }}$ \\
\hline 4 & $76,7^{\mathrm{AaBb}}$ & 4 & $78,3^{\text {Aabc }}$ & 4 & $75,4^{\mathrm{aBbc}}$ & 4 & $76,8^{\mathrm{AaBbc}}$ \\
\hline 5 & $77,3^{\text {Aab }}$ & 5 & $77,9^{\text {Aabc }}$ & 5 & $77,0^{\text {Aab }}$ & 5 & $77,0^{\text {Aabc }}$ \\
\hline 6 & $78,9^{\mathrm{Aa}}$ & 6 & $78,7^{\text {Aabc }}$ & 6 & $78,5^{\text {Aab }}$ & 6 & $79,0^{\text {Aa }}$ \\
\hline 7 & $74,9^{\mathrm{Ab}}$ & 7 & $75,6^{A c}$ & 7 & $74,6^{\mathrm{Abc}}$ & 7 & $74,3^{\text {Acd }}$ \\
\hline 8 & $76,0^{\text {Aab }}$ & 8 & $76,8^{\text {Aabc }}$ & 8 & $76,0^{\text {Aabc }}$ & 8 & $75,8^{\text {Abcd }}$ \\
\hline 9 & $77,0^{\mathrm{AaBb}}$ & 9 & $78,6^{\text {Aabc }}$ & 9 & $73,7^{\mathrm{Cc}}$ & 9 & $75,1^{\mathrm{BbCcd}}$ \\
\hline 10 & $74,6^{\mathrm{ABb}}$ & 10 & $75,8^{A b c}$ & 10 & $74,5^{\mathrm{ABbc}}$ & 10 & $73,0^{B d}$ \\
\hline 11 & $74,8^{\mathrm{Ab}}$ & 11 & $76,1^{A b c}$ & 11 & $74,2^{A b c}$ & 11 & $74,4^{\text {Acd }}$ \\
\hline 12 & $79,1^{\mathrm{AaB}}$ & 12 & $79,9^{\mathrm{Aa}}$ & 12 & $75,4^{\mathrm{abcc}}$ & 12 & $77,0^{\mathrm{aBbCc}}$ \\
\hline
\end{tabular}

DMS para comparar mês dentro de espécie $=3,11 \%$

DMS para comparar espécie dentro de mês $=2,43 \%$

Dentro de cada espécie, as médias que estão seguidas da mesma letra minúscula e dentro de cada mês as médias seguidas pela mesma letra maiúscula não diferem estatisticamente, pelo teste t múltiplo (ajuste single-step) ao nível de $5 \%$ de significância. 
Figura 1.Teor de umidade (\%) e teor de cinzas (\%) nas espécies no período analisado de março (1) de 2004 a fevereiro (12) de 2005.

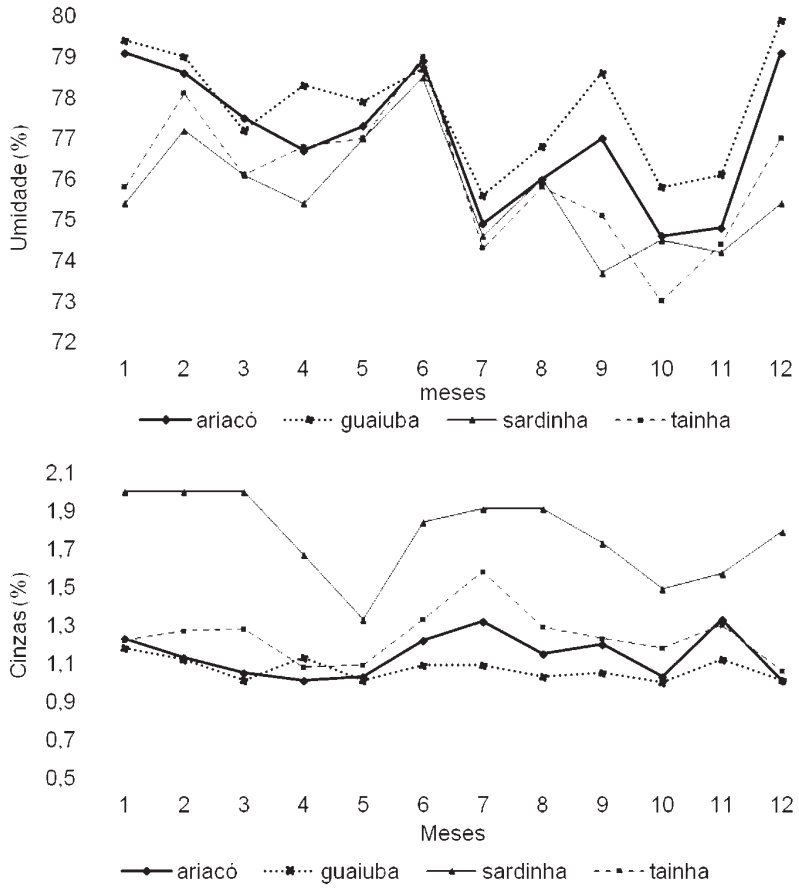

sardinha-laje (BTS) possui maior percentual que as espécies ariacó (PS), guaiuba (PS) e tainha (BTS). No entanto, esta última possui maior teor de cinzas que ariacó (PS). Para a diferença entre a tainha e guaiuba o $\mathrm{p}$-valor foi 0,049 . Para as demais diferenças o $p$-valor foi $<0,001$.

As substâncias voláteis que se decompõem pelo calor são eliminadas e a matéria orgânica é transformada em gás carbônico e água. Contudo, nos alimentos de origem marinha, poderá formar carbonato de sódio, caso uma quantidade do gás carbônico fique retido nas cinzas $^{17}$.

A faixa de variação do teor protéico determinada nas amostras de peixes está apresentada na Tabela 2. Dentre as espécies avaliadas, a tainha, espécie amostrada na BTS, apresentou o maior percentual em proteínas. Os valores encontrados no presente trabalho estão consistentes com os encontrados na literatura ${ }^{12,14-16}$.

De modo geral, na porção protéica dos peixes encontram-se os aminoácidos essenciais ao nosso organismo. Um estudo sobre a qualidade nutricional de peixes e alimentos marinhos ${ }^{20}$ concluiu que os peixes contém níveis de proteínas de 17 a $25 \%$, consistentes com valores encontrados no presente estudo.

Na comparação do teor de proteínas nas espécies dentro de cada mês (Tabela 2), os valores de magnitude de $1,27 \%$ ou maiores das diferenças de médias são significativos estatisticamente (inferência simultânea) ao nível de $5 \%$. Enquanto que entre meses dentro da espécie, os valores de $1,64 \%$ ou maiores é que foram estatisticamente significativos (Tabela 2).

A maior discrepância do teor protéico entre as espécies ocorreu nos meses de maio a julho de 2004. As espécies têm teores similares nos meses de abril, agosto, setembro e outubro de 2004 , enquanto em fevereiro de 2005 esses teores se apresentaram bem próximos (Figura 2).

Tabela 2.Teor médio de proteínas (\%) nas espécies no período analisado de março (1) de 2004 a fevereiro (12) de 2005

\begin{tabular}{|c|c|c|c|c|c|c|c|}
\hline mês & ariacó & mês & gaiúba & mês & sardinha & mês & tainha \\
\hline 1 & $18,8^{\text {Adef }}$ & 1 & $19,6^{\text {Aabcd }}$ & 1 & $19,0^{\mathrm{Ad}}$ & 1 & $19,7^{\text {Abcde }}$ \\
\hline 2 & $19,4^{\text {Abcde }}$ & 2 & $19,5^{\text {Aabcd }}$ & 2 & $19,5^{\mathrm{Acd}}$ & 2 & $18,9^{\mathrm{Ae}}$ \\
\hline 3 & $19,7^{\mathrm{aBbcde}}$ & 3 & $18,3^{\mathrm{Cd}}$ & 3 & $21,6^{\text {Aab }}$ & 3 & $21,0^{\mathrm{Abc}}$ \\
\hline 4 & $18,6^{\text {Bef }}$ & 4 & $18,9^{\mathrm{Bbcd}}$ & 4 & $21,1^{\text {Aabc }}$ & 4 & $20,3^{\text {Abcde }}$ \\
\hline 5 & $20,1^{\text {AaBbcde }}$ & 5 & $19,5^{\mathrm{aBbcd}}$ & 5 & $21,0^{\mathrm{Aabc}}$ & 5 & $21,3^{A b}$ \\
\hline 6 & $19,2^{\text {Acdef }}$ & 6 & $19,8^{\text {Aabcd }}$ & 6 & $19,9^{\text {Abcd }}$ & 6 & $19,5^{\text {Acde }}$ \\
\hline 7 & $17,6^{\mathrm{BCf}}$ & 7 & $18,6^{\mathrm{ABcd}}$ & 7 & $17,0^{\mathrm{Ce}}$ & 7 & $19,3^{\text {Ade }}$ \\
\hline 8 & $21,3^{\mathrm{aB}}$ & 8 & $20,4^{\mathrm{aBb}}$ & 8 & $22,6^{\mathrm{Aa}}$ & 8 & $23,2^{\mathrm{Aa}}$ \\
\hline 9 & $19,4^{\text {Bcde }}$ & 9 & $20,0^{\mathrm{AaBbc}}$ & 9 & $19,6^{\mathrm{ABcd}}$ & 9 & $20,8^{\mathrm{Abcd}}$ \\
\hline 10 & $20,4^{\text {Aabcd }}$ & 10 & $20,3^{\text {Aab }}$ & 10 & $21,4^{\text {Aab }}$ & 10 & $20,7^{\mathrm{Abcd}}$ \\
\hline 11 & $20,5^{\text {Aabc }}$ & 11 & $20,5^{\text {Aab }}$ & 11 & $20,7^{\mathrm{Abc}}$ & 11 & $21,2^{\mathrm{Ab}}$ \\
\hline 12 & $21,0^{\text {Aab }}$ & 12 & $21,1^{\mathrm{Aa}}$ & 12 & $20,8^{A b c}$ & 12 & $20,9^{\mathrm{Abcd}}$ \\
\hline
\end{tabular}

DMS para comparar mês dentro de espécie $=1,64 \%$

DMS para comparar espécie dentro de mês $=1,27 \%$

Dentro de cada espécie, as médias que estão seguidas da mesma letra minúscula e dentro de cada mês as médias seguidas pela mesma letra maiúscula não diferem estatisticamente, pelo teste t múltiplo (ajuste single-step) ao nível de $5 \%$ de significância. 
Figura 2. Teor de proteínas (\%) e teor de lipídios totais (\%) nas espécies no período analisado de março (1) de 2004 a fevereiro (12) de 2005.
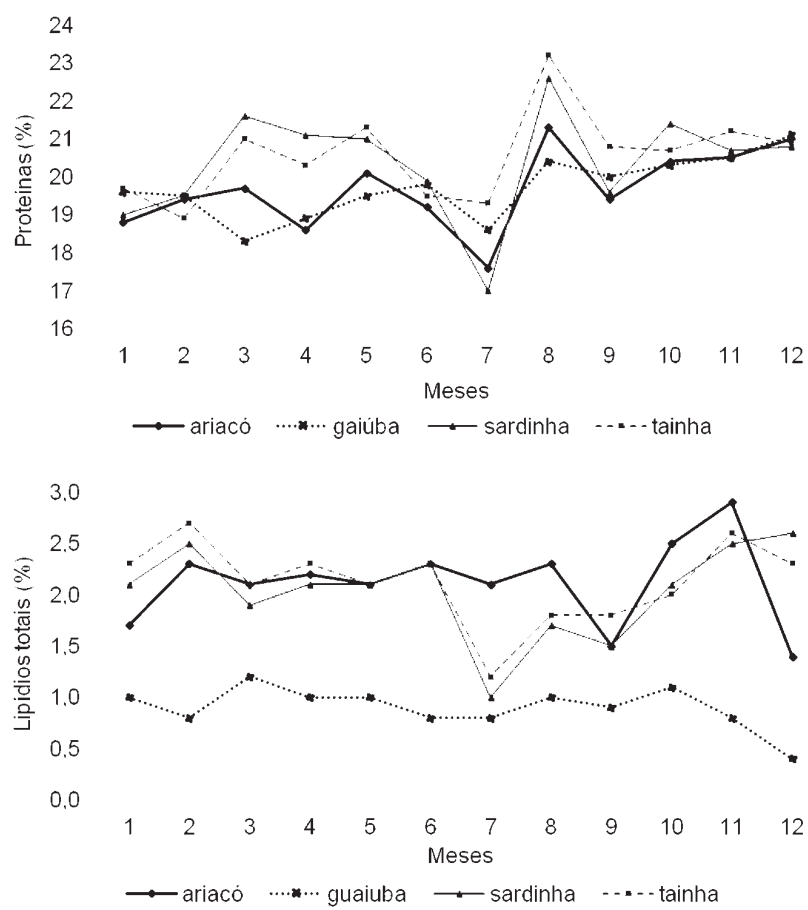

O teor de lipídios totais determinado no presente estudo está apresentado na Tabela 3 e é concordante com aqueles encontrados em trabalhos da literatura sobre tecido muscular de peixes ${ }^{12,13,16-20}$. O maior teor de lipídios totais foi observado na espécie ariacó e o menor, na guaiúba, ambas de Porto Seguro (Tabela 3).

Ariacó apresentou a maior fração lipídica dentre as espécies analisadas neste trabalho com teor similar ao encontrado na tainha (M. cephallus; $2,2 \%)^{16}$.

Diferenças de médias do teor de lipídios totais, nas espécies dentro de cada mês, foram avaliadas com magnitude de $0,52 \%$ ou maiores que são significativas estatisticamente (inferência simultânea) ao nível de 5\% (Tabela 3). De modo similar, para comparação das médias do teor de lipídios, nos meses, dentro de cada espécie, diferenças de médias de magnitude de 0,66 ou maiores são significativas estatisticamente (Tabela 3).

As espécies ariacó, sardinha e tainha tiveram comportamentos lipídicos similares nos meses de março a agosto de 2004 tendo a tainha o maior teor no mês de abril de 2004. A maior discrepância ocorreu nos meses de outubro de 2004 e janeiro de 2005 onde a espécie ariacó alcançou o maior teor. No período estudado, a espécie guaiuba apresentou o menor teor protéico (Figura 2).

A composição do teor dos lipídios totais, assim como o teor de umidade em peixes é um fator relevante quanto ao seu consumo devido à possibilidade de oxidação dos lipídios e deterioração do peixe desde a sua captura até ser adquirido pelo consumidor. De modo geral,

Tabela 3.Teor médio de lipídios (\%) nas espécies no período analisado de março (1) de 2004 a fevereiro (12) de 2005.

\begin{tabular}{cccccccc}
\hline mês & ariacó & mês & guaiuba & mês & sardinha & mês & tainha \\
\hline 1 & $1,7^{\text {Bcde }}$ & 1 & $1,0^{\mathrm{abc}}$ & 1 & $2,1^{\mathrm{AaBbc}}$ & 1 & $2,3^{\mathrm{Aab}}$ \\
2 & $2,3^{\mathrm{Aabc}}$ & 2 & $0,8^{\mathrm{Aab}}$ & 2 & $2,5^{\mathrm{Aab}}$ & 2 & $2,7^{\mathrm{Aa}}$ \\
3 & $2,1^{\text {Abcd }}$ & 3 & $1,2^{\mathrm{aB}}$ & 3 & $1,9^{\mathrm{Abc}}$ & 3 & $2,1^{\mathrm{Aab}}$ \\
4 & $2,2^{\mathrm{Abc}}$ & 4 & $1,0^{\mathrm{aBb}}$ & 4 & $2,1^{\mathrm{Aabc}}$ & 4 & $2,3^{\mathrm{Aab}}$ \\
5 & $2,1^{\mathrm{Abcd}}$ & 5 & $1,0^{\mathrm{aBB}}$ & 5 & $2,1^{\mathrm{Aabc}}$ & 5 & $2,1^{\mathrm{Aab}}$ \\
6 & $2,3^{\mathrm{Aabc}}$ & 6 & $0,8^{\mathrm{aBb}}$ & 6 & $2,3^{\mathrm{Aab}}$ & 6 & $2,3^{\mathrm{Aab}}$ \\
7 & $2,1^{\mathrm{Abcd}}$ & 7 & $0,8^{\mathrm{aBb}}$ & 7 & $1,0^{\mathrm{ABd}}$ & 7 & $1,2^{\mathrm{ABc}}$ \\
8 & $2,3^{\mathrm{Aabc}}$ & 8 & $1,0^{\mathrm{aC}}$ & 8 & $1,7^{\mathrm{Bc}}$ & 8 & $1,8^{\mathrm{ABb}}$ \\
9 & $1,5^{\mathrm{Ade}}$ & 9 & $0,9^{\mathrm{aBb}}$ & 9 & $1,5^{\mathrm{Acd}}$ & 9 & $1,8^{\mathrm{Abc}}$ \\
10 & $2,5^{\mathrm{Aab}}$ & 10 & $1,1^{\mathrm{aB}}$ & 10 & $2,1^{\mathrm{Aabc}}$ & 10 & $2,0^{\mathrm{Aab}}$ \\
11 & $2,9^{\mathrm{Aa}}$ & 11 & $0,8^{\mathrm{aBb}}$ & 11 & $2,5^{\mathrm{Aab}}$ & 11 & $2,6^{\mathrm{Aa}}$ \\
12 & $1,4^{\mathrm{Be}}$ & 12 & $0,4^{\mathrm{bC}}$ & 12 & $2,6^{\mathrm{Aa}}$ & 12 & $2,3^{\mathrm{Aab}}$ \\
\hline
\end{tabular}

DMS para comparar mês dentro de espécie $=0,67 \%$

DMS para comparar espécie dentro de mês $=0,52 \%$

Dentro de cada espécie, as médias que estão seguidas da mesma letra minúscula e dentro de cada mês as médias seguidas pela mesma letra maiúscula não diferem estatisticamente, pelo teste t múltiplo (ajuste single-step) ao nível de $5 \%$ de significância. 
os valores encontrados no presente estudo estão similares aos compilados para sardinha e outros pescados ${ }^{17}$. Os estudos realizados estão relacionados à mesma família e é fato que, variações podem ocorrer entre o teor de umidade, cinzas, proteínas e lipídios dentro da mesma espécie, em função de hábitos alimentares, da época, da idade, do sexo, da distribuição e origem dos organismos, dentre outros fatores ${ }^{21}$.

As variações na trajetória de crescimento, composição corporal e taxas de deposição de nutrientes são, até agora, melhores descritos do que explicados devido a sua complexidade ${ }^{22}$.

\section{CONCLUSÃO}

A umidade representou o principal componente $(73,0$ a $79,9 \%)$ do músculo dos peixes investigados. A sardinha-laje (Opisthonema oglinum), tainha (Mugil spp.), guaiúba (Ocyurus chrysurus) e ariacó (Lutjanus synagris) estudadas indicaram alto teor de proteínas ( $17 \%$ a $23,2 \%$ ) e baixos teores de lipídios podendo ser consideradas fontes protéicas relevantes. A sardinha-laje apresentou teor mais elevado em cinzas indicando maior conteúdo em minerais. A guaiuba apresentou maior teor de umidade e menor teor lipídico enquanto que, ariacó, está associada ao maior teor de lipídios totais. A tainha apresentou os maiores percentuais de proteínas. Os conteúdos de proteínas dos peixes variaram de acordo com a sazonalidade. As variações químicas que ocorreram foram cíclicas.

\section{AGRADECIMENTOS}

À FAPESB pelo suporte financeiro e à Profa. Dra. Janice Izabel Druzian do Laboratório de Pescado e Cromatografia Aplicada (LAPESCA) da Faculdade de Farmácia-UFBA pela aquisição das amostras de peixes.

\section{REFERÊNCIAS}

1. COSTA-NETO, Eraldo Medeiros. Restrições e preferências alimentares em comunidades de pescadores do município de Conde, Estado da Bahia, Brasil. Rev. Nutr., Campinas, v.13, n. 2, p: 117-126, 2000.

2. PIGOTT, George M., TUCKER Barbee W. Science opens new horizons for marine lipids in human nutrition. Food Rev Int, Philadelphia, v.3, n.1-2,p.105-138, 1987.

3. MENEZES M.E.S. et al. Composição centesimal, colesterol e perfil de ácidos graxos dos peixes tainha (Mugil cephalus) e camurim (Centropomus undecimalis) da Lagoa Mundaú, AL/Brasil. Rev. Inst. Adolfo Lutz. São Paulo, v. 67, n. 2, p: 89-95, 2008.

4. INSTITUTO BRASILEIRO DO MEIO AMBIENTE E DOS RECURSOS NATURAIS RENOVAVEIS. Boletim Estatístico da Pesca Marítima e Estuarina do Nordeste do Brasil, 2005. Tamandaré (PE): IBAMA/CEPENE. 2005. p. 29-79.

5. INSTITUTO BRASILEIRO DO MEIO AMBIENTE E DOS RECURSOS NATURAIS RENOVAVEIS. Boletim da Estatística da Pesca Marítima e Estuarina do Nordeste do Brasil, 2007. Tamandaré (PE): CEPENE, 2007. 217p.
6. VIANA, Zenira Cardoso VilasBoas. Avaliação da composição mineral e centesimal em peixes consumidos no Estado da Bahia. 2008. $155 \mathrm{f}$. Tese (Doutorado) - Instituto de Química,Universidade Federal da Bahia, Salvador, 2008.

7. OFFICIAL methods of analysis of AOAC International. 17th ed. Gaithersburg: Association of Official Analytical Chemists, 2000. 2000 p. 2v.

8. BLIGH, E.Graham, DYER, W.Justin. A rapid method of total lipid extraction and purification. Can. J. Biochem. Physiol., Ottawa, v. 37, n. 8, p: 911-17, 1959.

9. R DEVELOPMENT CORE TEAM. R: A language and environment for statistical computing. Vienna( Austria) : R Foundation for Statistical Computing, 2011.

10. THE R FOUNDATION FOR STATISCAL COMPUTING. R : Regulatory Compliance and Validation Issues A Guidance Document for the Use of $\mathbf{R}$ in Regulated Clinical Trial Environments. Viena. 2008. p. 1-23.

11. WESTFALL, Peter H. Multiple testing of general contrasts using logical constraints and correlations. J. Am. Statistical Assoc., New York, v. 92, n. 437, p. 299-306, 1997.

12. ANDRADE, G.Q; BISPO, E.S.; DRUZIAN, J.I. Avaliação da qualidade nutricional em espécies de pescado mais produzidas no Estado da Bahia. Ciênc. Tecnol. Aliment., Campinas, v. 29, n. 4, p: 721-26, 2009.

13. CAULA, F.C.B; OLIVEIRA, M.P; MAIA, E.L. Teor de colesterol e composição centesimal de algumas espécies de peixes do estado do Ceará. Ciênc. Tecnol. Aliment., Campinas, v. 28, n. 4, p. 959-63, 2008.

14. KÜÇÜKGÜLMEZ, A. et al. Effects of season on proximate and fatty acid compositions of two mediterranean fish - the round herring (Etrumeus teres) and tub gurnard (Chelidonichthys lucernus). Int. J. Food Sci. Technol., Oxford, v. 45, n. 5, p.1056-60, 2010.

15. SPITZ, J. et al. Proximate composition and energy content of forage species from the Bay of Biscay: high- or low-quality food? ICES J. Mar. Sci., Oxford, v. 67, n. 5, p: 909-15, 2010.

16. MENEZES, Maria Emilia da Silva. Valor nutricional de espécies de peixes (água salgada e estuário) do Estado de Alagoas, Maceió, 2006. 119 f. Dissertação (Mestrado), Pós-Graduação em Química e Biotecnologia, Universidade Federal de Alagoas, 2006.

17. UNIVERSIDADE DE CAMPINAS. Núcleo de Estudos e Pesquisas em Alimentação - NEPA. Tabela Brasileira de Composição de Alimentos. 2a ed. Campinas: Educamp; 2006. 114p.

18. LAMEU, Edson. Clínica Nutricional. São Paulo: Revinter; 2005. 1071p.

19. CUPPARI, Lilian. Guia de Nutrição: nutrição clínica no adulto. 2a ed. São Paulo: Manole; 2005. 490p.

20. KINSELLA, John E. Fish and Seafoods: Nutritional implications and quality issues. Food Technol., Chicago, v. 42, n. 5, p. 146-150, 1988.

21. CANLI M, Atly G. The relationships between heavy metal ( $\mathrm{Cd}, \mathrm{Cr}$, $\mathrm{Cu}, \mathrm{Fe}, \mathrm{Pb}, \mathrm{Zn}$ ) levels and the size of six Mediterranean fish species. Environ. Pollut., Barking, v. 121, n. 1, p. 129-36, 2003.

22. DUMAS, A; FRANCE, J; BUREAU, D. Modelling growth and body composition in fish nutrition: where have we been and where are we going? Aquac. Res., West Sussex, v. 41, n. 2, p. 161-81, 2010.

Submetido em 05.02.2013;

Aceito em 05.08.2013. 